\title{
Effect of Deformation Heating on Microstructure Evolution During Hot Forging of Ti-6Al-4V
}

\author{
MYKOLA KULAKOV, SALAHEDDIN RAHIMI, and S. LEE SEMIATIN
}

The effect of deformation heating on microstructure evolution during hot forging of Ti-6Al-4V was established. For this purpose, right-circular cylinders of Ti-6Al-4V with an equiaxed- $\alpha$ preform microstructure were preheated to a temperature between $1148 \mathrm{~K}\left(875^{\circ} \mathrm{C}\right)$ and $1223 \mathrm{~K}$ $\left(950{ }^{\circ} \mathrm{C}\right)$, and compressed to a 60 -pct. height reduction in a screw press, yielding average true strain rates of $\sim 5$ to $20 \mathrm{~s}^{-1}$. Thermocouple measurements and corroborating finite-element-method (FEM) simulations quantified substantial deformation-heating-induced temperature increases. For all preheat temperatures, the heating transient led to an exposure above the equilibrium $\beta$ transus temperature. Despite such temperature excursions, the volume fraction of equiaxed primary $\alpha$ in each forged billet was only slightly lower than that in the corresponding preheated condition. The source of such observations was rationalized on the basis of the (hypothesized) solute-concentration fields that develop during the heating and cooling transients experienced in high-rate deformation processing.

https://doi.org/10.1007/s11661-021-06493-1

(C) The Author(s) 2021

\section{INTRODUCTION}

HiGH-INTEGRITY structural components are often fabricated via thermomechanical processes consisting of a series of bulk-forming operations and intermediate and final heat treatments. The starting stock is usually manufactured from large ingots that are worked in hydraulic presses or slabbing mills to produce semi-finished wrought products with a uniform, recrystallized grain structure. Subsequently, sections of the mill product are cut and shaped by closed-die forging. Such forging operations are usually conducted using a variety of types of equipment including hydraulic, mechanical, screw presses or forging hammers, each with its own ram-position-versus-time characteristics. ${ }^{[1,2]}$ In conventional processes using these types of equipment, the workpiece is preheated to a high temperature and shaped between dies that are at room temperature or a slightly elevated temperature.

MYKOLA KULAKOV is with the Boeing Research and Technology Europe, 85 Inchinnan Drive, Renfrew, PA4 9LJ, UK. Contact e-mail: nkulako@gmail.com SALAHEDDIN RAHIMI is with the Advanced Forming Research Centre, University of Strathclyde, 85 Inchinnan Drive, Renfrew, PA4 9LJ, UK. S. LEE SEMIATIN is with the Air Force Research Laboratory, Wright Patterson Air Force Base, OH 45433-7817.

Manuscript submitted June 1, 2021; accepted October 8, 2021.

Article published online November 18, 2021
Hydraulic presses, characterized by a nominally constant ram speed, are the slowest of the presses and impart strain rates of the order of 0.1 to $2 \mathrm{~s}^{-1}$. These presses are best suited for forging thick cross-section workpieces for which die chill (i.e., loss of heat between the work material and dies) is of minor importance. For the forging of thin components for which die chill must be minimized, however, mechanical and screw presses are often selected; these machines impart deformation at strain rates of $\sim 10$ to $100 \mathrm{~s}^{-1}$. Forging hammers provide even higher strain rates, $\sim 100$ to $500 \mathrm{~s}^{-1}$, but deformation is imposed in a series of consecutive and relatively small strain increments.

Irrespective of strain and specific forging equipment, the majority of the work of deformation is converted to heat, and the balance is stored as defects (e.g., dislocations, vacancies, grain boundaries) in the crystal lattice. Per the pioneering contributions of Taylor and Quinney, ${ }^{[3]}$ the fraction converted to heat is typically taken to be $\sim 90$ pct, although more recent investigations have suggested that the actual fraction may change during deformation depending on the specific workpiece material, the deformation temperature, etc. ${ }^{[4,5]}$ It is this deformation heating that gives rise to measurable increases in the instantaneous workpiece temperature. The exact temperature rise per se is a function of local strain, heat transfer between regions undergoing different strains within the workpiece, and die chill. Needless to say, the complexity of heat generation and transport can give rise to noticeable spatial variations in the temperature field during conventional forging. Furthermore, the internal regions of a large workpiece forged 
under high-rate conditions may actually experience a temperature rise that can be characterized as adiabatic.

The occurrence of deformation heating can have a major effect on plastic flow and microstructure evolution during hot forging, especially for two-phase aerospace materials such as titanium-base alloys and nickel-base superalloys. For both of these alloy systems, the high-temperature phase (bcc $\beta$ in $\alpha / \beta$ titanium alloys and fcc $\gamma$ in the superalloys) is much softer than the low-temperature phase (hcp $\alpha$ in $\alpha / \beta$ titanium alloys and fcc $\gamma^{\prime}$ in superalloys). Thus, temperature changes during hot working may produce flow softening associated with changes in the instantaneous phase proportions, which in turn can lead to macroscopically non-uniform plastic flow and inhomogeneous microstructure evolution, ${ }^{[6-8]}$ and, as a result, poor service properties.

Several recent investigations ${ }^{[9,10]}$ have examined the interaction of temperature transients, deformation, and the evolution of microstructure in in Ti-6Al-4V with a starting equiaxed $\alpha$ microstructure. In particular, the kinetics of dissolution or growth of primary- $\alpha$ particles during heating or cooling, respectively, were measured and interpreted using simple diffusion analyses. This prior work suggested that concurrent deformation tends to enhance the rate of $\alpha$-phase dissolution during heating but appears to have little to no effect on the rate of growth during cooling, at least for relatively-slow strain rates $\left(0.01,0.1 \mathrm{~s}^{-1}\right)$. It is unclear whether such trends also pertain to higher strain rates that characterize conventional forging in mechanical/screw presses or hammers, let alone industrially-important solid-state joining processes such as linear- and inertia- friction welding. In addition, it was found recently that $\alpha / \beta$ forging conditions appear to play an important role in controlling the relative magnitude of the deformation of the $\alpha$ and $\beta$ phases and associated development of crystallographic texture during near-transus forging. Under certain circumstances, improper selection of forging variables may result in the formation of a deleterious, coarse- $\beta$-grain structure during subsequent $\beta$ annealing in Ti-6Al-4V. ${ }^{[11]}$

The present work was designed therefore to meet two principal objectives: (1) To establish the level of deformation heating during high rate deformation processing of Ti-6Al-4V and (2) to determine how such heating transients affect the evolution of the $\alpha$ and $\beta$ phases. To meet these objectives, instrumented, hot-compression tests were performed at various temperatures in a screw press, and the resulting microstructures were measured and interpreted in terms of the associated temperature transients.

\section{MATERIALS AND PROCEDURES}

\section{A. Materials}

The material used in the present work was provided by TIMET Savoie in the form of a $\varnothing 335 \mathrm{~mm}$ billet section of Ti-6Al-4V. The chemical composition (in weight percent) was: $6.31 \mathrm{Al}, 4.10 \mathrm{~V}, 0.16 \mathrm{Fe}, 0.18 \mathrm{O}$, $0.03 \mathrm{C}, 0.01 \mathrm{~N}$, balance titanium. The $\beta$ transus temperature of $1274 \mathrm{~K}\left(1001{ }^{\circ} \mathrm{C}\right)$ was measured by the material supplier using the metallographic method by fitting a regression line to the volume fraction of primary- $\alpha$ obtained in samples preheated to various temperatures below and above the expected $\beta$ transus temperature; the zero primary- $\alpha$ intercept of the calculated linear function corresponded to the reported value of the $\beta$ transus temperature. The initial room-temperature microstructure comprised equiaxed $\alpha$ particles with an average circle-equivalent diameter of $14 \mu \mathrm{m}$ lying in a matrix of transformed $\beta$. Measurements of $\alpha$ grain size were conducted on the axial-radial direction plane using MIPAR software ${ }^{[12]}$ and a semi-automated image analysis technique. A number of slightly oversized cylinders, each with a height-to-diameter ratio of 1.5 , was extracted using electrical-discharge machining from the as-received billet and then finished on a lathe to the final dimensions. Three different cylinder sizes were used in the experimental program: $\varnothing 45 \times 67.5 \mathrm{~mm}, \varnothing 65 \times$ $97.5 \mathrm{~mm}$, and $\varnothing 85 \times 127.5 \mathrm{~mm}$ (Figure 1).

\section{B. Experimental Procedures}

Following machining, the surface of each compression cylinder was coated with glass to minimize contamination in air at high temperatures as well as to provide lubrication during hot forging. To determine temperature transients during (and following) forging, each billet was instrumented with $\varnothing 0.5 \mathrm{~mm}$ N-type thermocouples having a nominal response time of $30 \mathrm{~ms}$. For this purpose, thermocouples were embedded at the mid-height plane of each cylinder, one at the mid-radius and the other at its centre. Temperature readings were collected using a National Instruments data-acquisition board and Signal Express software operating at a sampling rate of $1000 \mathrm{~Hz}$. After preparation, each cylinder was preheated in an electric furnace for a time between 2000 and 3000 seconds at a test temperature of $1148 \mathrm{~K}, 1173 \mathrm{~K}, 1198 \mathrm{~K}$ or $1223 \mathrm{~K}\left(875^{\circ} \mathrm{C}, 900{ }^{\circ} \mathrm{C}, 925\right.$ ${ }^{\circ} \mathrm{C}$ or $950{ }^{\circ} \mathrm{C}$ ). An additional $25 \times 50 \times 50 \mathrm{~mm}$

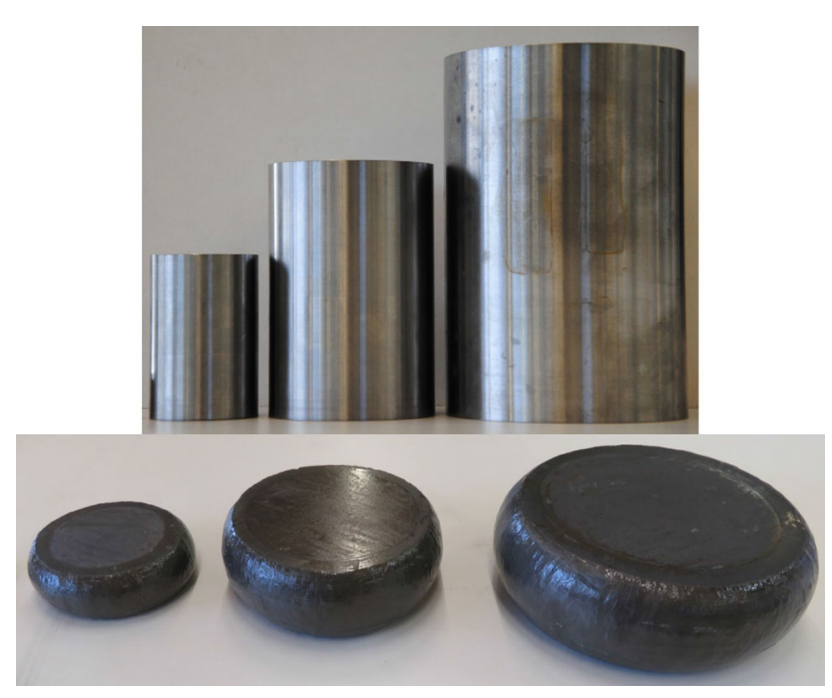

Fig. 1-As-machined $\varnothing 45, \varnothing 65$, and $\varnothing 85 \mathrm{~mm}$ cylinders and billets after forging at $1223 \mathrm{~K}\left(950{ }^{\circ} \mathrm{C}\right)$. 
glass-coated specimen was placed in the furnace at each of the four test temperatures and water quenched without forging to establish the nominally-equilibrium microstructure immediately before forging.

Forging trials were conducted in a 2100-tonne Schuller screw press using flat dies. The top die was preheated to $523 \mathrm{~K}\left(250^{\circ} \mathrm{C}\right)$, while the lower die was at $503 \mathrm{~K}\left(230{ }^{\circ} \mathrm{C}\right)$. The dies were sprayed with a waterbased graphite lubricant immediately before forging. In all cases, cylinders were upset to a reduction of 60 pct or an average axial height strain of $\sim 0.9$. One $\varnothing 45 \mathrm{~mm}$ cylinder was forged at each of the four subtransus temperatures; one $\varnothing 65$ and one $\varnothing 85 \mathrm{~mm}$ cylinder were also forged at $1223 \mathrm{~K}\left(950^{\circ} \mathrm{C}\right)$. For all experiments, the average ram velocity was $\sim 600 \mathrm{~mm} / \mathrm{s}$, thus providing a true axial strain rate during forging (= ram velocity/ instantaneous height) in the range between $\sim 5$ and 20 $\mathrm{s}^{-1}$. For the reduction chosen, the duration of the forging blow was thus $\sim 0.07$ or 0.15 seconds for the $\varnothing 45$ and $\varnothing 85 \mathrm{~mm}$ cylinders, respectively. Following forging, each deformed billet was removed from the dies as quickly as possible and water quenched.

\section{Metallographic Procedures}

The four un-deformed specimens and six upset cylinders were sectioned axially and polished for microstructure examination using standard metallographic procedures. The microstructure of each as-polished billet was examined using an FEI Quanta 650 field-emission gun scanning electron microscope (SEM) equipped with a backscatter electron (BSE) and NordlysMax ${ }^{3}$ electron backscatter diffraction (EBSD) detectors. For all SEM observations, an accelerating voltage of $20 \mathrm{kV}$ was employed. $\mathrm{Z}$ contrast in BSE micrographs provided excellent differentiation of the primary- $\alpha$ particles (appearing dark) and the $\beta /$ transformed $\beta$ (appearing light); the resulting microstructures were analyzed using MIPAR image-analysis software ${ }^{[12]}$ to quantify the volume fractions of each phase in the un-deformed specimens and at various locations in the forged billets. To this end, 15 micrographs were captured at $\times 750$ (the total analyzed area being $\sim 0.75$ $\mathrm{mm}^{2}$ ) and used to determine the average volume fractions of $\alpha$ and $\beta$. In addition, EBSD maps were collected at the centre of the $\varnothing 45$ and $\varnothing 85 \mathrm{~mm}$ forged cylinders. For these evaluations, the scanned area was $106 \times 73 \mu \mathrm{m}$ with a step size of $0.125 \mu \mathrm{m}$. Grains were differentiated using a boundary misorientation cutoff of $5^{\circ}$ using the MTEX Matlab toolbox ${ }^{[13]}$ followed by manual partitioning of the orientation data between primary $\alpha$ and transformed $\beta$. The kernel average misorientation (KAM) was calculated using a relatively large $9 \times 9$ pixel size to minimize noise in KAM maps. The combination of large KAM pixels and the fine EBSD scan step size would still permit to detect any small variations in intragranular misorientation within primary- $\alpha$ particles.

\section{RESULTS}

The key results of this investigation consisted of measured temperature transients during hot forging and observations of the resulting evolution of microstructure in the Ti-6Al-4V billets.

\section{A. Temperature Transients}

Thermocouple measurements during processing of the $\varnothing 45 \mathrm{~mm}$ Ti-6Al-4V cylinder at $1173 \mathrm{~K}\left(900{ }^{\circ} \mathrm{C}\right)$ (Figure 2) showed that the temperature decreased only slightly during the transfer from the furnace to the press and while resting on the bottom die before forging. The extent of the temperature decrease was greater at the mid-radius location compared to the centre, as expected. By contrast, during forging, the centre of the cylinder experienced the highest temperature increase with a heating rate exceeding $100 \mathrm{~K} / \mathrm{s}$. During forging and post-forging cooling, the temperature remained above the $\beta$ transus $\left(1274 \mathrm{~K}\right.$, or $1001{ }^{\circ} \mathrm{C}$ ) for $\sim 0.4$ second. After

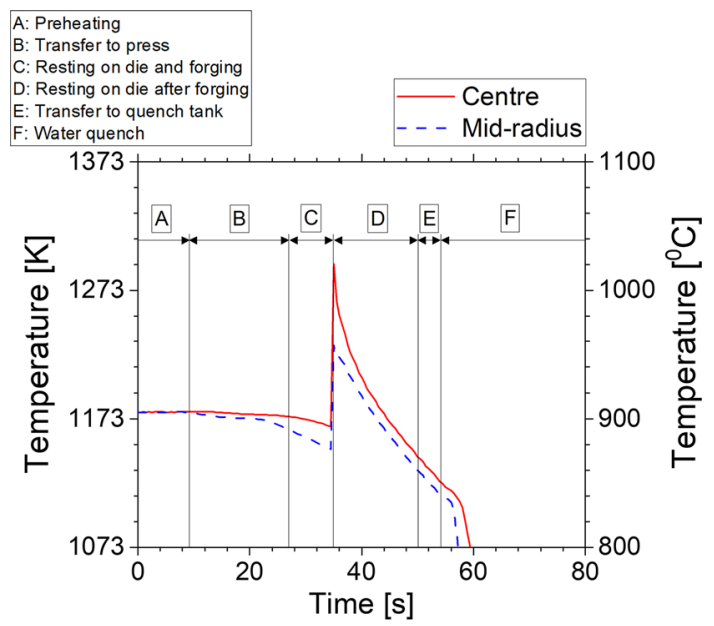

(a)

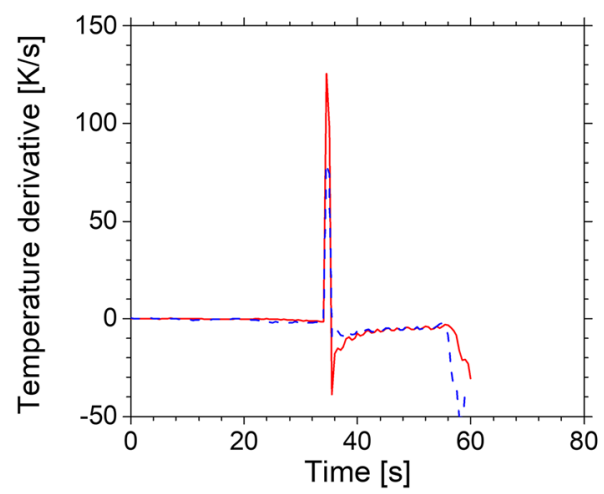

(b)

Fig. 2-(a) Measured temperature transients during forging of a $\varnothing 45$ $\mathrm{mm}$ cylinder at $1173 \mathrm{~K}\left(900{ }^{\circ} \mathrm{C}\right)$ and $(b)$ the corresponding temperature derivatives. 
the initial rapid cooling immediately after forging, the cooling rate remained at $\sim 6 \mathrm{~K} / \mathrm{s}$ during resting on the bottom die and during the transfer to the quench tank. Once the cylinder was placed in water, the cooling rate increased to $\sim 50 \mathrm{~K} / \mathrm{s}$; the temperature at which this increase in cooling rate occurred was $\sim 850{ }^{\circ} \mathrm{C}$.

Thermocouple temperature measurements at the centre of $\varnothing 45 \mathrm{~mm}$ cylinders forged at 1148, 1173 and 1198 $\mathrm{K}\left(875{ }^{\circ} \mathrm{C}, 900{ }^{\circ} \mathrm{C}\right.$ and $\left.925{ }^{\circ} \mathrm{C}\right)$ are summarized in Table I. As the forging temperature increased, the deformation-heating-induced temperature spike decreased. Nevertheless, higher preheat temperatures resulted in corresponding longer times above the $\beta$ transus.

The measured temperature transients revealed that the overall magnitude of the temperature increase due to deformation heating during forging at $1223 \mathrm{~K}\left(950{ }^{\circ} \mathrm{C}\right)$ did not depend on the size of the cylinder (Figure 3 and Table II). However, the heating rates were greater during forging of the small-diameter cylinders inasmuch as the time to achieve the required height reduction decreased with the cylinder size for the constant ram velocity used in the present work. In addition, the time above the $\beta$ transus increased from 1.3 to 5.1 seconds at the centre of $\varnothing 45$ and $\varnothing 85 \mathrm{~mm}$ cylinders, respectively, due to slower cooling after forging of the larger billets. The centre of the $\varnothing 45 \mathrm{~mm}$ cylinder also experienced faster cooling during water quenching in $\sim 10$ seconds after forging; most of this time was associated with the interval required to transfer the billet from the press to the water tank. In contrast, a fast cooling rate at the centre of the $\varnothing 85 \mathrm{~mm}$ cylinder was achieved only after $\sim 25$ seconds with the post-forging handling time being only slighly longer compared to the $\varnothing 45 \mathrm{~mm}$ cylinder. Moreover, cooling rates in the quench tank were greatly reduced as the cylinder size increased (i.e., from $\sim 30$ to 8 $\mathrm{K} / \mathrm{s}$ during water quenching of $\varnothing 45$ and $\varnothing 85 \mathrm{~mm}$ cylinders, respectively).

\section{B. Microstructure Observations}

The as-forged microstructures after forging at $1148 \mathrm{~K}$, $1173 \mathrm{~K}, 1198 \mathrm{~K}$ or $1223 \mathrm{~K}\left(875^{\circ} \mathrm{C}, 900,925^{\circ} \mathrm{C}\right.$ or 950 ${ }^{\circ} \mathrm{C}$ ) were interpreted relative to the nominally-equilibrium structures developed in billets during initial preheating at three subtransus temperatures followed by water quenching (Figure 4). At each preheating temperature, the equilibrium microstructure consisted of an ensemble of equiaxed, primary- $\alpha$ particles in a matrix of transformed $\beta$, the latter constituent evolved from the high-temperature $\beta$ matrix [Figures 4(a) through (c)].
The micrographs revealed a clear trend of a decrease in the volume fraction of $\alpha$ with increasing temperature.

After forging at $1148 \mathrm{~K}, 1173 \mathrm{~K}$ and $1198 \mathrm{~K}\left(875^{\circ} \mathrm{C}\right.$, $900{ }^{\circ} \mathrm{C}$, and $925^{\circ} \mathrm{C}$ ), substantial amounts of primary $\alpha$ were observed at the centre of each of the $\varnothing 45 \mathrm{~mm}$ cylinders [Figures 4(d) through (f)], thus suggesting that the $\alpha \rightarrow \beta$ phase transformation had not been completed as a result of transient heating to a temperature above the equilibrium $\beta$ transus. Observations of elongation of the primary $\alpha$ particles (relative to that in the preheated condition) also suggested that this phase had accommodated measurable strain despite its greater flow stress relative to that of the $\beta$ phase. ${ }^{[14]}$ Quantitative image analysis results (Figure 5) (previously reported in ${ }^{[15]}$ ) revealed that the fraction of transformed $\beta$ (i.e., fraction of $\beta$ at high temperature) was only slightly higher compared to that in the corresponding billets which were water quenched after preheating alone. In addition, the increase in the percentage of $\beta$ was greater during forging at lower temperatures for which the temperature increase per se was greatest (Table I).

Similarly to the observations made above for lower subtransus temperatures, changes in the aspect ratio of the primary $\alpha$ particles after forging at $1223 \mathrm{~K}\left(950{ }^{\circ} \mathrm{C}\right)$ suggest that deformation of both $\alpha$ and $\beta$ phases contributed to the overall shape change of the cylinders (Figure 6). An un-dissolved primary $\alpha$ was still present at the centre of $\varnothing 45, \varnothing 65$, and $\varnothing 85 \mathrm{~mm}$ cylinders preheated at $1223 \mathrm{~K}\left(950{ }^{\circ} \mathrm{C}\right)$ prior to forging. These observations thus indicated that even $\sim 5 \mathrm{~s}$ above the $\beta$ transus during forging of a $\varnothing 85 \mathrm{~mm}$ cylinder was not sufficient to complete $\alpha \rightarrow \beta$ dissolution during forging and post-forging cooling. In fact, the percentage of $\beta$ (and remnant equiaxed $\alpha$ ) did not vary significantly with cylinder size or location (Figure 7). In all cases, the percentage of $\beta$ was close to the level in the preheated-and-water-quenched billet.

Insight into the possibility that the $\beta$ phase grew substantially (and $\alpha$ dissolved concurrently) during deformation heating and then transformed back to $\alpha$ during post-forging cooling was clarified via EBSD measurements. In such a case, the $\alpha$ phase present at the peak temperature experienced during forging might be distinguishable from that which may have formed by growth during cooling following forging based on local variations in stored work/dislocation substructure. This possibility was elucidated in the band contrast and kernel average misorientation (KAM) maps derived from EBSD data collected at the centre of the $\varnothing 45$ and $\varnothing 85 \mathrm{~mm}$ cylinders which had experienced a large difference in the maximum time above the $\beta$ transus

Table I. Temperature Measurements at the Centre of $\varnothing 45 \mathrm{~mm}$ Cylinders During Forging at $1148 \mathrm{~K}, 1173 \mathrm{~K}$ and $1198 \mathrm{~K}\left(875{ }^{\circ} \mathrm{C}\right.$, $900{ }^{\circ} \mathrm{C}$, and $\left.925^{\circ} \mathrm{C}\right)$.

\begin{tabular}{lcr}
\hline Furnace Temperature $[\mathrm{K}]\left(\left[{ }^{\circ} \mathrm{C}\right]\right)$ & Temperature Increase $[\mathrm{K}]$ & Time Above $\beta$ Transus $[\mathrm{s}]$ \\
\hline $1148(875)$ & 138 & 0.3 \\
$1173(900)$ & 108 & 0.4 \\
$1198(925)$ & 89 & 0.7 \\
\hline
\end{tabular}


during forging, i.e., 1.3 vs. 5.1 seconds, respectively (Figure 8). The band contrast maps did not reveal any notable features within the primary $\alpha$ that would suggest its partial dissolution during post-forging cooling [Figures 8(b) and (f)]. In the KAM maps, most of the primary $\alpha$ particles exhibited high levels of KAM. Furthermore, the level of KAM for the primary $\alpha$ at the centre of $\varnothing 45$ and $\varnothing 85 \mathrm{~mm}$ cylinders appeared to be similar [Figures 8(c) and (g)]. In particular, no regions suggestive of epitaxial growth of primary $\alpha$ during cooling (i.e., $\alpha$ particles with high KAM at the centre and low KAM near the edges) were discerned. However, there were some $\alpha$ particles with low levels of KAM overall. It is likely that these latter particles consisted of high Taylor-factor orientations that suffered little deformation within the soft $\beta$ matrix during forging.

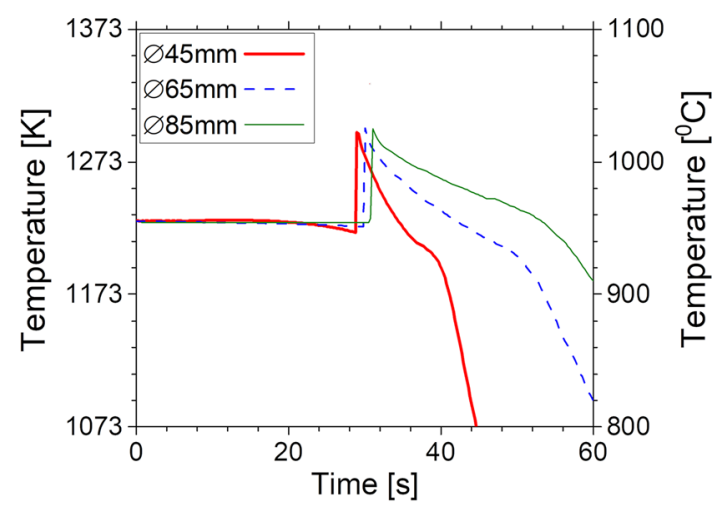

(a)

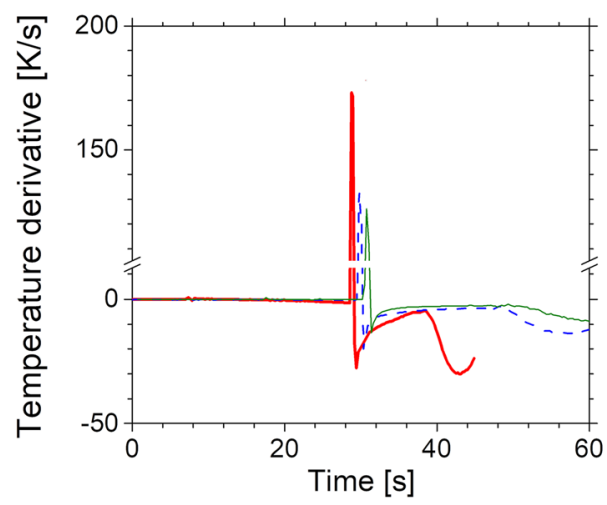

(b)

Fig. 3-(a) Measured temperature transients at the centre of $\varnothing 45$, $\varnothing 65$, and $\varnothing 85 \mathrm{~mm}$ cylinders during forging at $1223 \mathrm{~K}\left(950{ }^{\circ} \mathrm{C}\right)$ and (b) the corresponding temperature derivatives.

\section{DISCUSSION}

In this section, the effect of temperature transients on the extent of $\alpha \rightarrow \beta$ dissolution during forging was assessed using a microstructure evolution model. Results of finite element simulations are then presented along with possible sources of difference between experimental observations and simulations of temperature transients.

\section{A. Microstructure Evolution}

For Ti-6Al-4V with an equiaxed- $\alpha$ starting microstructure, temperature transients may be hypothesized to affect the kinetics of $\alpha$-particle dissolution (during increasing temperatures) or growth (under decreasing temperature conditions). Assuming that these phenomena are diffusion-controlled, a broad insight into transient microstructure evolution during the present forging experiments was obtained.

The dissolution behavior of equiaxed $\alpha$ during the heating ramp from the (initial) furnace temperature to the peak temperature experienced at the end of the forging stroke was estimated using the one-dimensional diffusion analysis described in Reference 9. The key input parameters consisted of the initial (lognormal) size distribution of the $\alpha$ particles (assumed to be spherical), the initial and final (peak) temperatures, the diffusivity of the rate-limiting solute (assumed to be vanadium), and the equilibrium composition (vanadium) of the two phases. ${ }^{[14]}$

In the present work, two different combinations of initial/peak temperature were treated $1148 \mathrm{~K} / 1286 \mathrm{~K}$ and $1223 \mathrm{~K} / 1299 \mathrm{~K}$, per the results in Tables I and II, each assuming a linear heating ramp corresponding to a 60 -pct reduction of a $67.5-\mathrm{mm}$-high $(\varnothing 45 \mathrm{~mm})$ cylinder at a $\mathrm{ram}$ velocity of $600 \mathrm{~mm} / \mathrm{s}$, i.e., $\sim 0.07$ s. The initial (average) $\alpha$ particle radii and volume fractions were taken to be $8 \mu \mathrm{m}$ and 0.67 for the lower preheat temperature and $3.25 \mu \mathrm{m}$ and 0.30 for the higher preheat temperature. The pipe-diffusion-enhanced diffusivity of vanadium through the concurrently-deforming $\beta$ phase was assumed to follow the relation: ${ }^{[9]}$

$$
D_{\mathrm{V}}\left(\mu \mathrm{m}^{2} / \mathrm{s}\right)=1.2 \times 10^{6} \exp (-17461 / T(K))
$$

Last, because of the short duration of the forging stroke and concomitant short diffusion distance, soft impingement of the concentration fields was neglected. By this means, an upper bound on the amount of $\alpha$-phase dissolution was obtained.

Table II. Temperature Measurements at the Centre of Ø45, Ø65, and Ø85 mm Cylinders During Forging at $1223 \mathrm{~K}\left(950{ }^{\circ} \mathrm{C}\right)$.

\begin{tabular}{lcc}
\hline Preform Size $[\mathrm{mm}]$ & Temperature Increase $[\mathrm{K}]$ & Time Above $\beta$ Transus [s] \\
\hline$\varnothing 45 \times 67.5$ & 76 & 1.3 \\
$\varnothing 65 \times 97.5$ & 74 & 2.7 \\
$\varnothing 85 \times 127.5$ & 71 & 5.1 \\
\hline
\end{tabular}



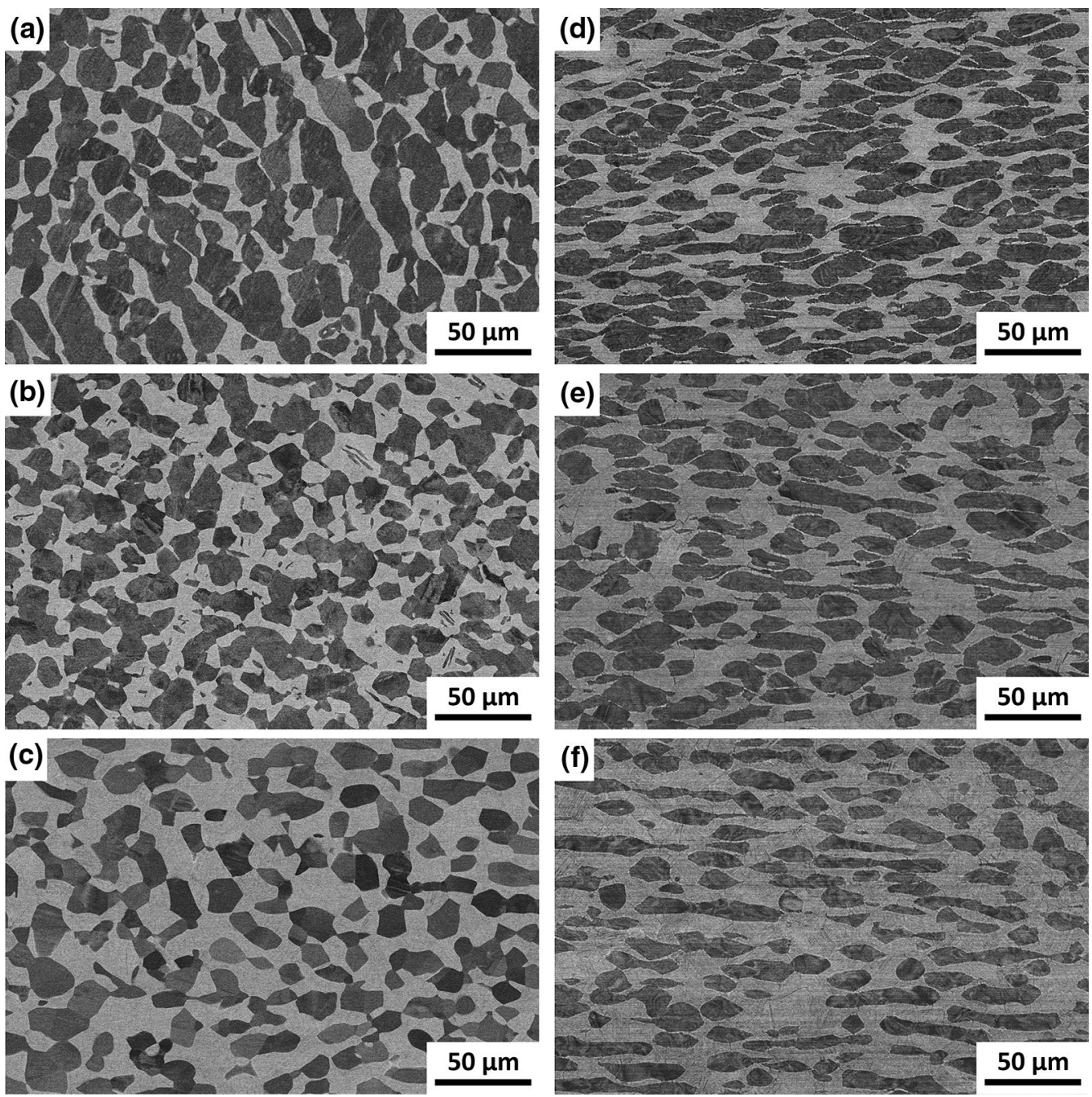

Fig. 4-Microstructures developed during water quenching after preheating alone at $(a) 1148 \mathrm{~K}\left(875{ }^{\circ} \mathrm{C}\right),(b) 1173 \mathrm{~K}\left(900{ }^{\circ} \mathrm{C}\right)$ or $(c) 1198 \mathrm{~K}(925$ $\left.{ }^{\circ} \mathrm{C}\right)$; microstructures developed at the centre of $\varnothing 45 \mathrm{~mm}$ cylinders after forging at $(d) 1148 \mathrm{~K}\left(875^{\circ} \mathrm{C}\right),(e) 1173 \mathrm{~K}\left(900^{\circ} \mathrm{C}\right)$, or $(f) 1198 \mathrm{~K}\left(925^{\circ} \mathrm{C}\right)$ (the forging direction is vertical).

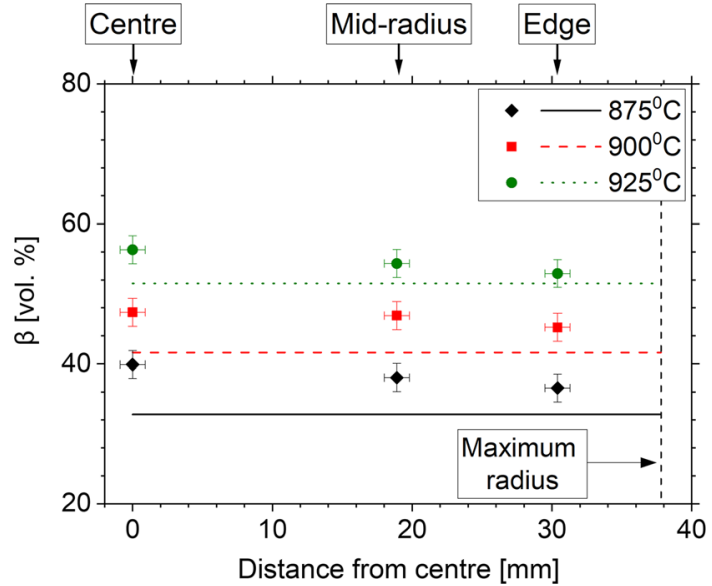

Fig. 5-Radial distribution of $\beta$ percentage at the mid-height plane of $\varnothing 45 \mathrm{~mm}$ cylinders forged at three subtransus temperatures. The symbols represent measurements for the forged cylinders, and the solid lines are measurements of the $\beta$ fraction in undeformed material. The error bars correspond to one standard deviation. (Reprinted from Ref. 15, under the terms of the Creative Commons Attribution License CC BY 4.0.).
Diffusion calculations for the forging portion of the processing cycle (Figure 9) suggested that relatively little of the equiaxed- $\alpha$ is dissolved during heating transients imparted during forging in a screw press. Specifically, for both examples considered here, a volume fraction of only $\sim 0.03$ to 0.04 was predicted to dissolve during heating. Slightly higher amounts of $\alpha$ dissolution would be predicted for higher final forging temperatures. In any case, the predictions are very similar to those observed experimentally after forging, transfer, and water quenching (Figures 5 and 7). In-situ observations of the $\alpha \rightarrow \beta$ phase transformation during gas tungsten arc welding of a Ti-6Al-4V alloy using spatially resolved synchrotron diffraction showed that during heating at $42.7 \mathrm{~K} / \mathrm{s}$ a superheat of $169 \mathrm{~K}$ was required to achieve full dissolution of $\alpha$ phase. ${ }^{[16]}$ The effect of heating rate (within the range of 0.25 to $200 \mathrm{~K} / \mathrm{s}$ ) on kinetics of the $\alpha$ $\rightarrow \beta$ phase transformation in a Ti-6Al-4V alloy during continuous heating from room temperature was also studied using high-energy synchrotron diffraction. ${ }^{[17]}$ For highest heating rates, the actual rate of heating in 

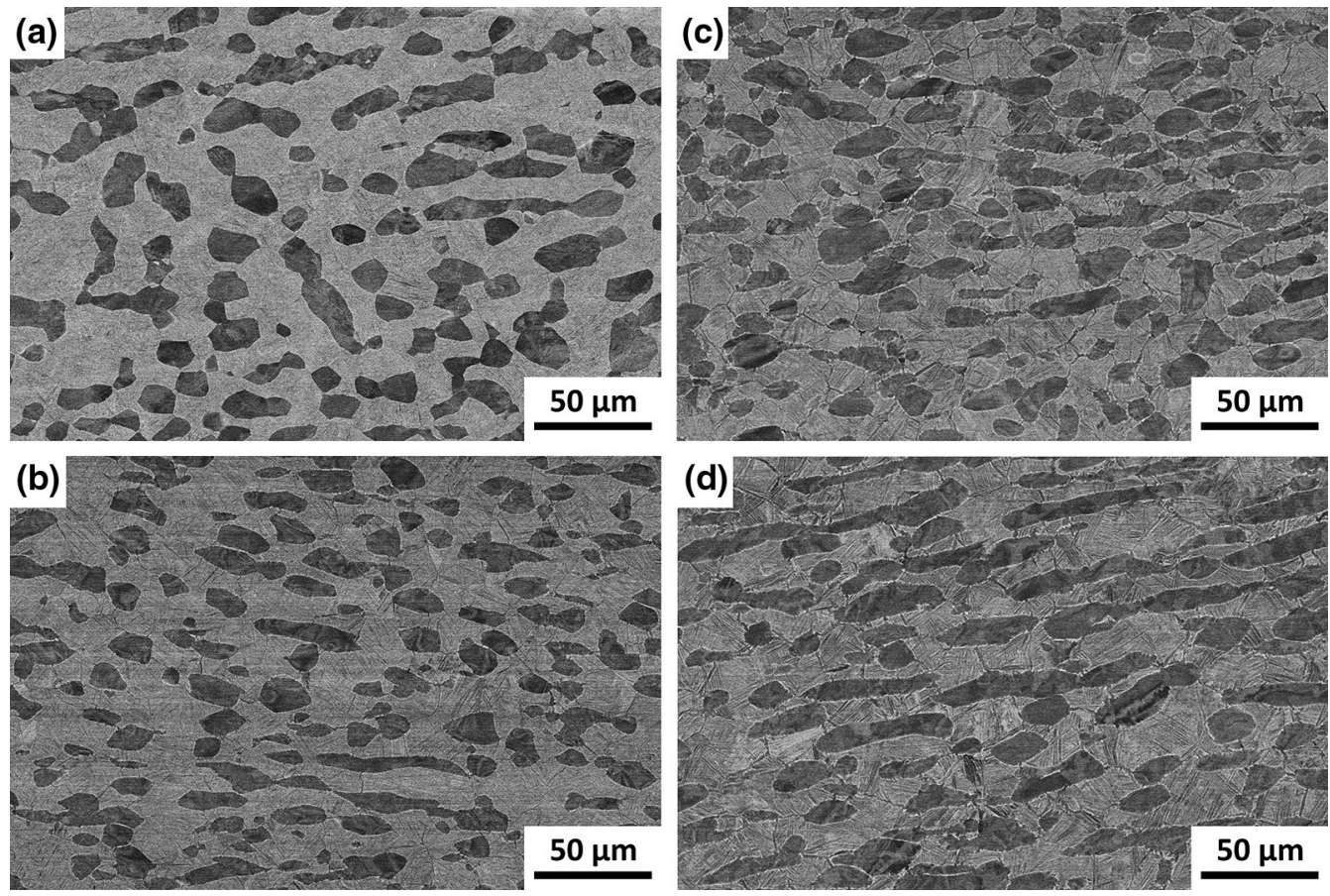

Fig. 6- (a) Microstructure developed during water quenching after preheating alone at $1223 \mathrm{~K}\left(950{ }^{\circ} \mathrm{C}\right)$; microstructures developed at the centre of $(b) \varnothing 45,(c) \varnothing 65$, or $(d) \varnothing 85 \mathrm{~mm}$ cylinders after forging at $1223 \mathrm{~K}\left(950{ }^{\circ} \mathrm{C}\right)$ (the forging direction is vertical).

the transformation temperature range was significantly lower than the nominal value due to limitations of the resistance heating equipment. Nevertheless, it was shown that by increasing nominal heating rate from 0.25 to $200 \mathrm{~K} / \mathrm{s}$, the temperature for the completion of the $\alpha \rightarrow \beta$ phase transformation increased from $1288 \mathrm{~K}$ $\left(1015{ }^{\circ} \mathrm{C}\right)$ to $1348 \mathrm{~K}\left(1075{ }^{\circ} \mathrm{C}\right)$. Similar to the experimental observations and modelling results in the present study, as heating rate increases, the time available for the diffusion-controlled $\alpha \rightarrow \beta$ phase transformation reduces thus leading to an increase in the $\beta$ transus.

Additional consideration of the nature of diffusion-limited transformations involving a heating and cooling cycle may provide the reason for the similarity of $\alpha$-phase-dissolution predictions based solely on the heating-cycle analysis and the actual experimental observation. As shown schematically in Figure 10, this explanation is couched in the nature of the transient concentration profiles that may be developed during such temperature reversals. During high-rate forging of Ti-6Al-4V, the rate-controlling solute (vanadium) diffuses toward $\alpha$ particles, i.e., it diffuses down a smooth concentration gradient toward the $\alpha-\beta$ interface (indicated by the red curve in Figure 10), and the $\alpha$ particles dissolve. Assuming that this process is diffusion controlled, the $\beta$ matrix concentration at the interface is assumed to be that which is in equilibrium with the $\alpha$ particle at each instant of time and temperature.

Once forging has been completed and the temperature starts to decrease, a markedly-different concentration profile may be expected to develop, however. In this case, it is assumed that the $\beta$ composition at the $\alpha-\beta$ interface adjusts instantaneously to maintain equilibrium with the adjacent $\alpha$ particle. For relatively rapid cooling conditions, on the other hand, the remainder of the concentration profile developed during forging may not equilibrate quickly, and a non-monotonic concentration profile may result (blue curve in Figure 10). This behavior would result in the development of a location of zero concentration gradient and thus zero solute flux. Such a zero-flux condition located near the $\alpha-\beta$ interface would thus limit further dissolution of $\alpha$ particles and thus explain the observation of little effect of time above the $\beta$ transus on the resulting volume fractions of the two phases.

\section{B. Forging Simulations}

To quantify the local strain, strain rate, and temperature histories within each upset billet, two-dimensional, axisymmetric finite-element-method (FEM) simulations of the forging process were performed using the commercial software DEFORM. For these calculations, the workpiece material (Ti-6Al-4V) was assumed to be rigid-viscoplastic, and the upper and lower dies were considered as rigid bodies. A mechanical-to-thermal energy conversion ratio (Taylor-Quinney factor) of 0.9 was used for each of the simulations. The thermal conductivity and heat capacity of the workpiece and die materials were taken from data available in the open literature. ${ }^{[18]}$ Furthermore, a workpiece-air heat transfer coefficient of $20 \mathrm{~W} / \mathrm{m}^{2} \mathrm{~K}$ provided a good agreement between the measured thermocouple data and the simulated temperature changes during billet transfer prior to forging. Workpiece-die heat transfer coefficients were taken to be 500 and $11000 \mathrm{~W} / \mathrm{m}^{2} \mathrm{~K}$ during free resting of the billet on the dies and during the forging operation, respectively. A constant friction shear factor 


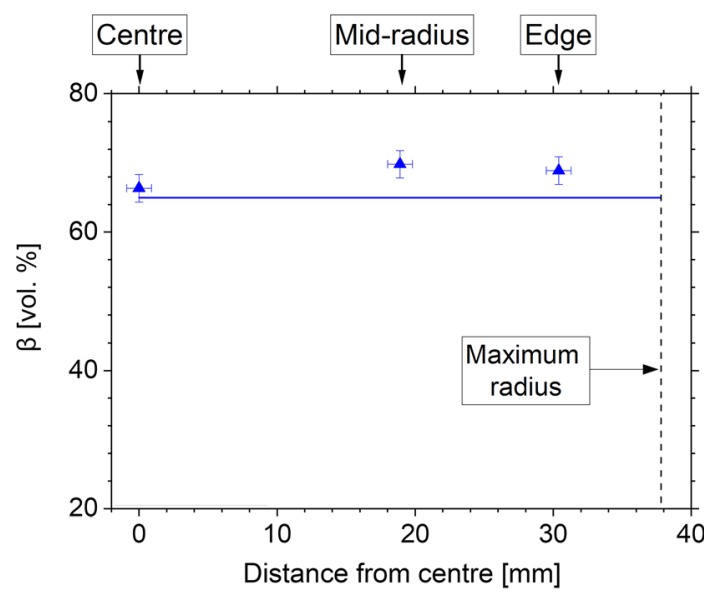

(a)

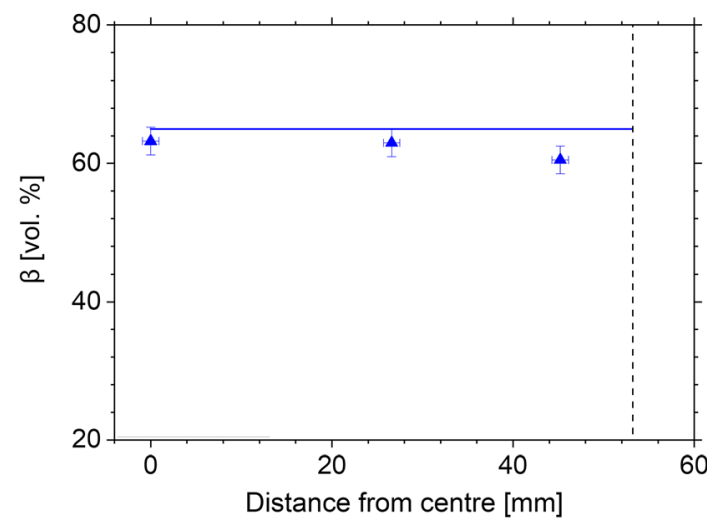

(b)

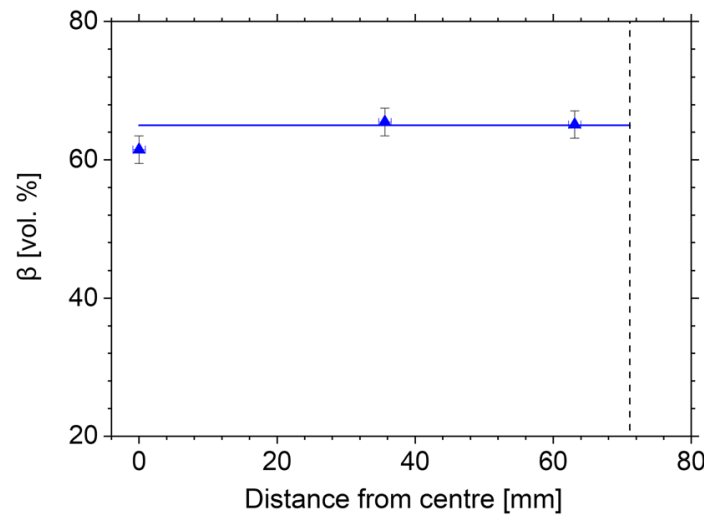

(c)

Fig. 7-Radial distribution of $\beta$ percentage at the mid-height plane of $(a) \varnothing 45,(b) \varnothing 65$, and $(c) \varnothing 85 \mathrm{~mm}$ cylinders forged at $1223 \mathrm{~K}$ $\left(950{ }^{\circ} \mathrm{C}\right)$. The symbols represent measurements for the forged cylinders, and the solid lines are measurements of the $\beta$ fraction in undeformed material. The error bars correspond to one standard deviation. ((a) reprinted from Ref. 15, under the terms of the Creative Commons Attribution License CC BY 4.0).

of 0.3 between the workpiece and the dies was assumed for all simulations. Videos of the forging trials were used to quantify transfer times of the workpiece to/from the press, and the velocity of the upper die was measured experimentally to complete the input dataset for the FEM simulations.
Two approaches were taken to obtain the constitutive properties of Ti-6Al-4V for the FEM simulations. In the first approach, isothermal compression test data for Ti-6Al-4V with an equiaxed microstructure were taken from Reference 8 . The shortcoming of this approach is that it does not consider the fact that $\alpha$ phase remains present in the microstructure during rapid deformation-induced heating even above the transus; instead the equilibrium volume fractions of the $\alpha$ and $\beta$ phases and equilibrium phase compositions are assumed for all temperatures. For the other approach, the flow stress input for the finite element model was estimated using an approximate self-consistent viscoplastic technique with composition-dependent properties of the two phases as described in Reference 14. This modelling methodology is particularly useful for evaluating the effect of temperature transients on flow stress. ${ }^{[9,14]}$ For temperatures at and above the starting forging temperature, flow stress was calculated using the chemical composition of the Ti-6Al-4V alloy employed in this study and the volume fractions of the $\alpha$ and $\beta$ phases in the undeformed and water quenched specimens; the predicted dissolution of primary $\alpha$ (Figure 9) during forging was also accounted for in the flow stress model. For temperatures below the starting forging (preheat) temperature, isothermal compression test data from Reference 8 were used, inasmuch as near-equilibrium phase fractions were likely to have been established during furnace heating and relatively slow cooling during the furnace-to-press transfer and while resting on the bottom die prior to forging.

When isothermal flow stress data were used as input in the FE model, the predicted forging loads were significantly underestimated (Figure 11). Much more realistic estimate of the loads required to upset the cylinders were obtained when implementing flow stress data estimated using the self-consistent model taking into an account the effect of temperature, strain rate, and the $\alpha / \beta$ phase fractions. In such instances, the retention of a higher-than-equilibrium volume fraction of the $\alpha$ phase is likely the source of the harder response that was both measured and simulated.

A macrograph of the $\varnothing 45 \mathrm{~mm}$ Ti-6Al-4V cylinder forged at $1223 \mathrm{~K}\left(950{ }^{\circ} \mathrm{C}\right)$ [Figure 12(a)] and the corresponding FEM simulation results [Figures 12(b) through (d)] provided further insight into material response over the entire billet section. Mirroring the metal-flow pattern in the macrograph, the FEM-predicted effective strain distribution [Figure 12(b)] was highly non-uniform. The highest strains were experienced at the centre, while the top and bottom regions of the cylinder that had been in contact with the dies underwent virtually no deformation; i.e., the latter consisted of so-called "dead-metal" zones. The shape of the contours quantifying the distribution of maximum temperature during the forging process [Figure 12(c)] were very similar to those of the strain-distribution map. These results indicated that a large part of the cylinders had experienced substantial deformation heating. However, the temperature was predicted to exceed the $\beta$ transus in only a small $(\sim 5 \times$ $20 \mathrm{~mm})$ area at the centre of the workpiece. Moreover, 

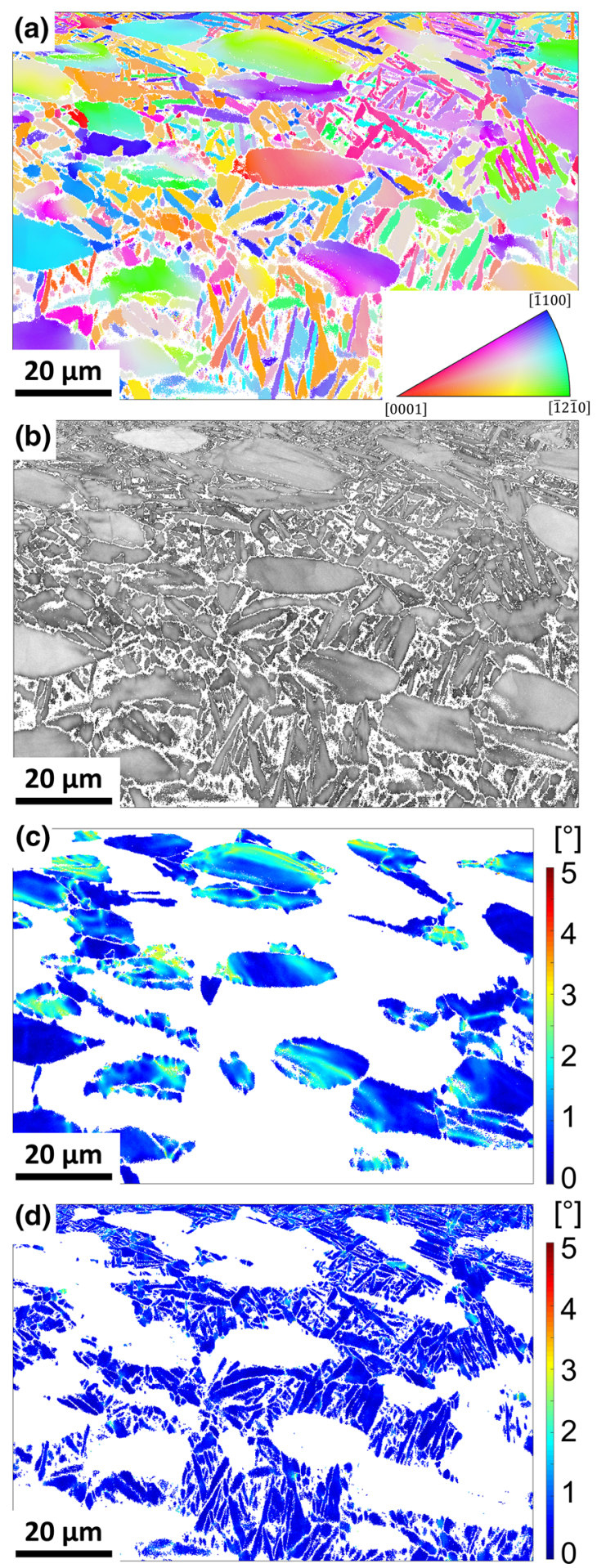
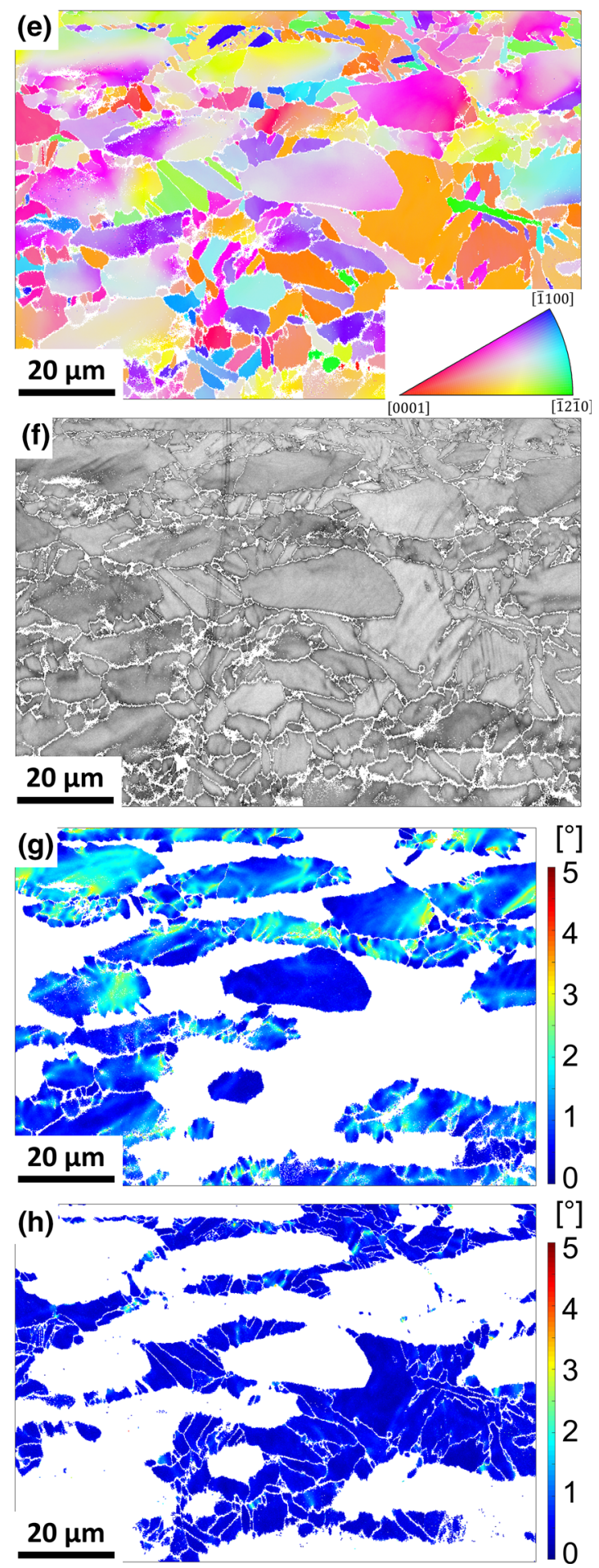

Fig. 8- $(a, e)$ Measured $\alpha$-phase EBSD inverse-pole-figure maps for the forging direction $(b, f)$ band contrast maps (c, $g)$ KAM distributions within the equiaxed, primary $\alpha$, and $(d, h)$ KAM distributions within the transformed $\beta$. (a to d) Correspond to the $\varnothing 45$ mm cylinder, and (e through $h$ ) are for the $\varnothing 85 \mathrm{~mm}$ cylinder, both forged at $1223 \mathrm{~K}\left(950{ }^{\circ} \mathrm{C}\right)$. The forging direction is vertical in all micrographs.

the region between the centre and the mid-radius at the mid-height (equatorial) plane experienced temperatures above the transus for the longest time [Figure 12(d)]. However, this location did not correspond to that at which the highest strain had been achieved due to the nature of heat transfer in the upset cylinder after the forging blow.
Both the macrograph and FEM-simulated strain distribution map for the $\varnothing 85 \mathrm{~mm}$ cylinder forged at $1223 \mathrm{~K}\left(950^{\circ} \mathrm{C}\right)$ [Figures $13(\mathrm{a})$ and (b)] indicated a more uniform deformation compared to the $\varnothing 45 \mathrm{~mm}$ cylinder [Figures 12(a) and (b)]. The temperature distribution map [Figure 13(c)] mimicked the strain distribution map highlighting that even with a slightly longer forging 


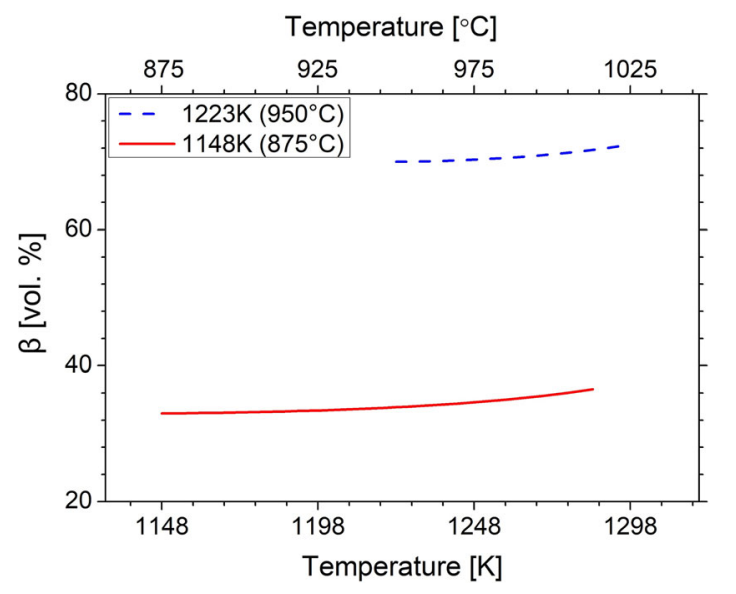

Fig. 9-Diffusion predictions of the dissolution of equiaxed, primary $\alpha$ during heating transients involving preheat/peak temperatures of $1148 \mathrm{~K} / 1286 \mathrm{~K}$ and $1223 \mathrm{~K} / 1299 \mathrm{~K}$ for the screw-press forging of 67.5 -mm-high $(\varnothing 45 \mathrm{~mm})$ Ti-6Al-4V cylindrical preforms to a 60 -pct. height reduction.

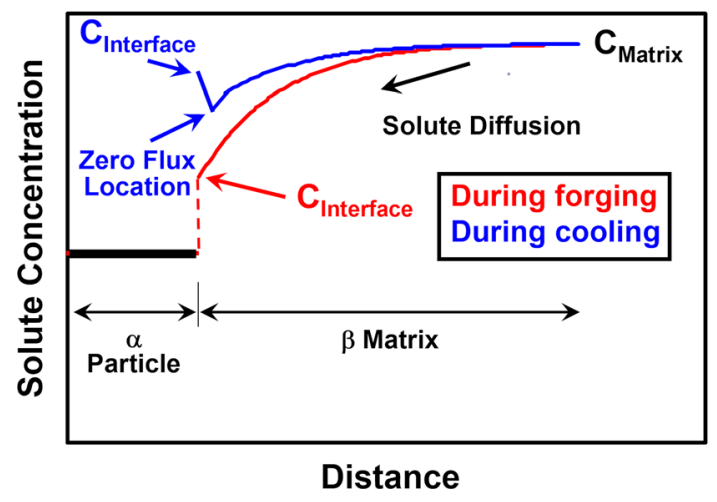

Fig. 10-Schematic illustration of the vanadium concentration profiles that may develop during a temperature reversal such as that which occurs during conventional forging.

blow there was insufficient time during forging for the redistribution of the generated heat. Furthermore, in comparison to the $\varnothing 45 \mathrm{~mm}$ cylinder, the central part of the $\varnothing 85 \mathrm{~mm}$ cylinder was predicted to experience a much longer time above the $\beta$ transus, $\sim 10 \mathrm{~s}$, at locations between the centre and mid-radius in the mid-height plane.

Heating and cooling rates based on thermocouple measurements during and immediately after forging were significantly lower than FEM-simulated temperature changes at the centre of the $\varnothing 45 \mathrm{~mm}$ billet forged at $1223 \mathrm{~K}\left(950^{\circ} \mathrm{C}\right)$ [Figures 3(b) and 14(b)]. As a result, the peak in the experimental temperature-time curve was not fully resolved and simulated peak temperatures tended to be higher [Figures 3(a) and 14(a)]. These differences between the experimental temperature data and simulation results were observed for all other cylinder sizes and forging temperatures as well.

Any one of a number of factors may influence the measured or simulated temperature histories and thus the comparison of such behaviors. The accuracy of the $\mathrm{N}$-type thermocouple employed in this study $( \pm 5 \mathrm{~K}$ at

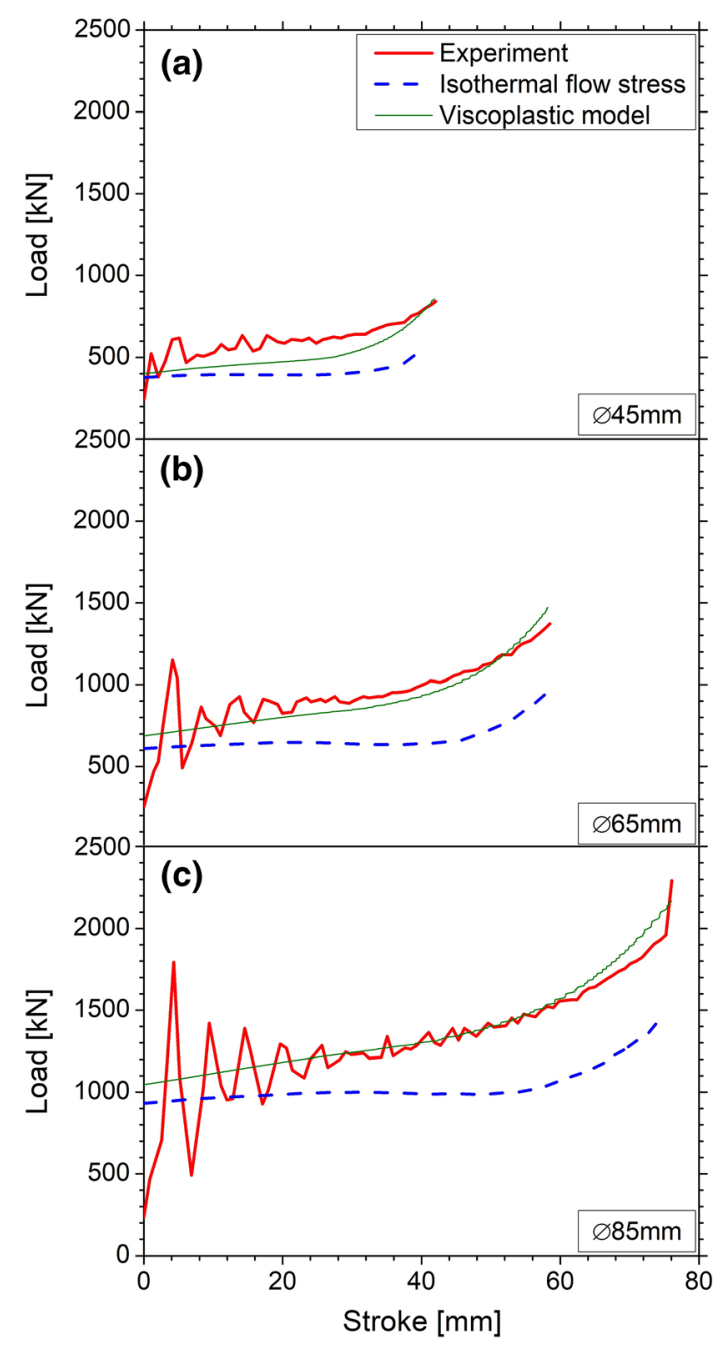

Fig. 11-Comparison of experimentally-measured and FEM-predicted forging loads using two different material flow stress inputs for $(a) \varnothing 45,(b) \varnothing 65$, and (c) Ø85 mm cylinders forged at $1223 \mathrm{~K}\left(950^{\circ} \mathrm{C}\right)$.

the forging temperatures) can account for only a small fraction of the difference in the measured and simulated temperature histories. Other uncertainties can arise from errors associated with the finite response time of the thermocouple design, the exact location of the thermocouple(s), and poor contact between the thermocouple and workpiece developed during preheating and/or forging. With regard to the first factor, the thermocouple response time of $0.03 \mathrm{~s}$ was not sensitive enough to capture the temperature increase during the forging blow which took only $\sim 0.07$ to $0.15 \mathrm{~s}$ (depending on the cylinder size).

Simulated time-temperature plots [Figure 14(a)] highlight how sensitive the peak temperature is to small variations in the exact position of the thermocouple in regions of high temperature gradient. For future forging trials with embedded thermocouples, therefore, the precise position of the thermocouple in as-forged condition should be verified using a non-destructive examination technique (such as X-ray computed tomography) or serial sectioning. 

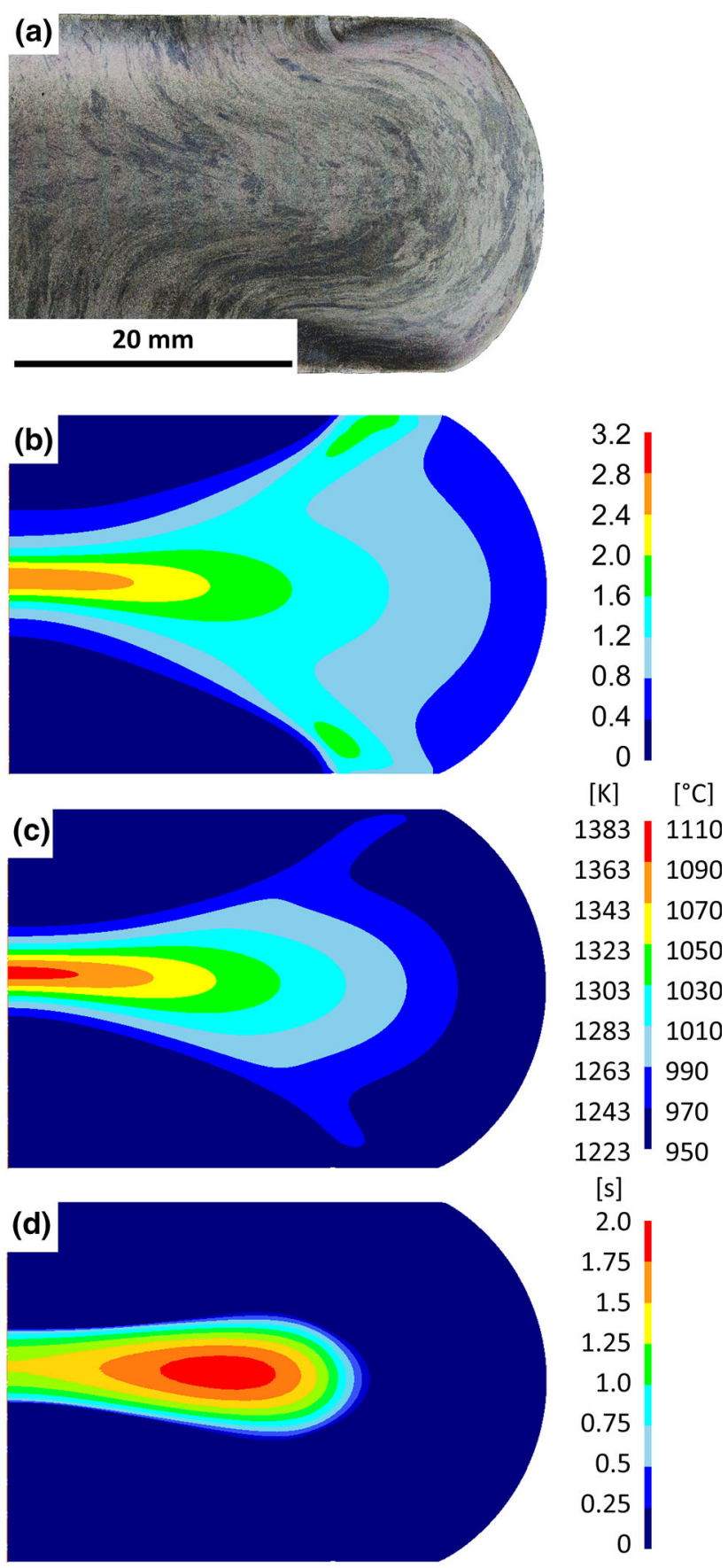

Fig. 12-(a) Macrostructure developed during forging of the Ø45 mm Ti-6Al-4V cylinder at $1223 \mathrm{~K}\left(950{ }^{\circ} \mathrm{C}\right)$, and FEM predictions of (b) effective strain, $(c)$ maximum temperature, and $(d)$ time above the $\beta$ transus.

Last, the thermocouple well and the thermocouple itself can present a discontinuity in the workpiece material, which may affect the local plastic deformation and temperature distribution in adjacent areas during forging. The effect of an embedded object in the cylinders on material flow was minimized by using thin $\varnothing 0.5 \mathrm{~mm}$ thermocouples, which also provided a faster response compared to larger thermocouples. Furthermore, a small discontinuity in material flow (and/or difference in thermal expansion coefficients between the
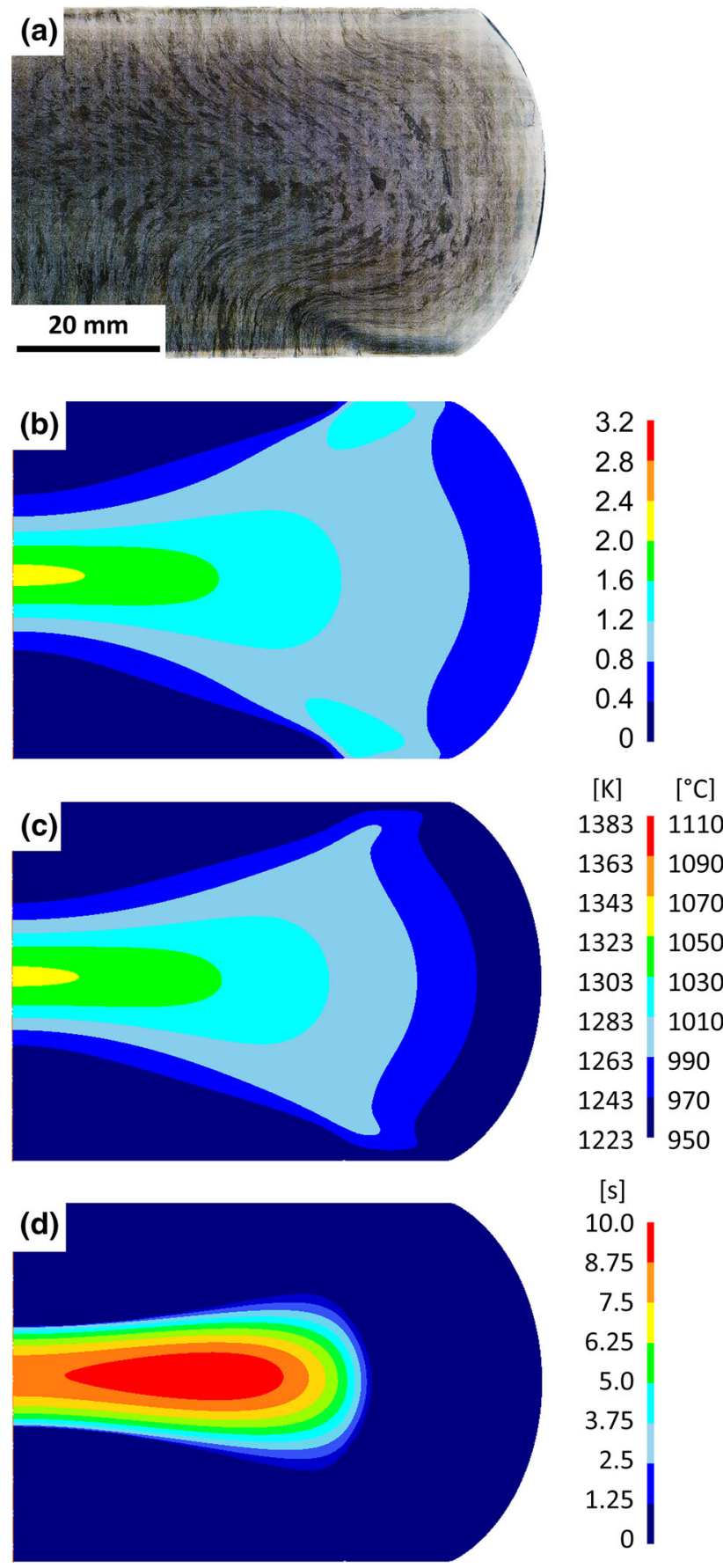

Fig. 13-(a) Macrostructure developed during forging of the $\varnothing 85$ $\mathrm{mm}$ Ti-6Al-4V cylinder at $1223 \mathrm{~K}\left(950{ }^{\circ} \mathrm{C}\right)$ and FEM predictions of $(b)$ effective strain, $(c)$ maximum temperature and $(d)$ time above the $\beta$ transus.

thermocouple and workpiece materials) could produce a gap which would change the heat transfer mechanism from conduction to radiation, thus also affecting response time.

With regard to the FEM simulations of the temperature histories, there are also several sources of error and/or uncertainty. These include the exact magnitude of the Taylor-Quinney factor $(\chi)$, the input flow stress $\sigma$ [as a function of strain $(\varepsilon)$, strain rate $(\dot{\varepsilon})$, temperature 


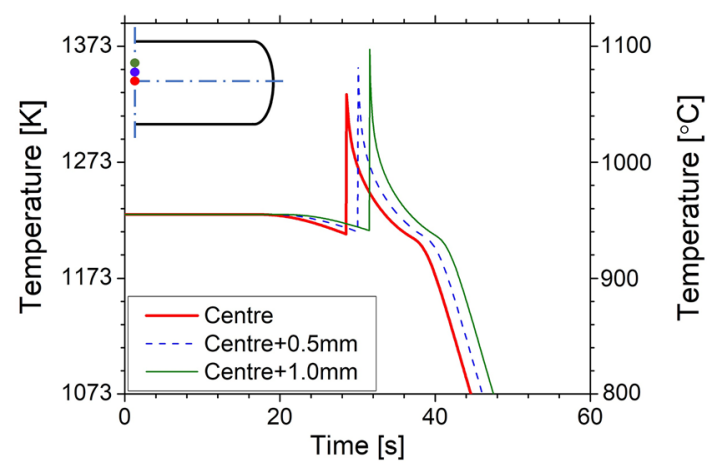

(a)

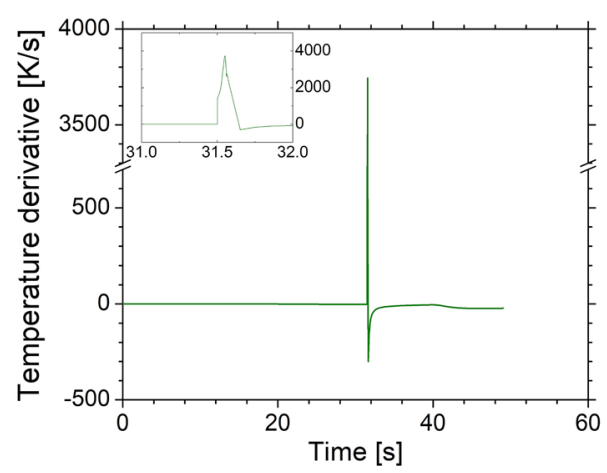

(b)

Fig. 14-(a) Simulated temperature changes for three locations in the centre of the $\varnothing 45 \mathrm{~mm}$ Ti-6Al-4V cylinder forged at $1223 \mathrm{~K}$ (950 ${ }^{\circ} \mathrm{C}$ ) (the curves are offset along the $X$-axis to enable comparison), $(b)$ temperature derivative for one of the three locations shown in (a) (centre of the forged cylinder $+1 \mathrm{~mm}$ along the $Y$-axis).

(T), and instantaneous microstructure], the specific heat (c), etc. Each of these quantities enters into the following expression assuming that heat transfer can be neglected when the workpiece is deformed rapidly:

$$
\int \mathrm{d} T=\chi \int \frac{\sigma}{\rho \cdot c} \mathrm{~d} \varepsilon
$$

Here, $\rho$ denotes the density of the workpiece material.

Material properties are typically evaluated under equilibrium conditions. For example, the importance of taking into account the effect of actual phase fractions rather than equilibrium phase content on flow stress per se was demonstrated in Figure 11; the contribution of hard $\alpha$ phase on the overall mechanical response of the material was essential to achieve a good agreement between the simulated and experimental load-stroke data. The fraction of mechanical energy converted into thermal energy, i.e., the Taylor-Quinney factor, is typically assumed to be 0.9 (including this study). However, recent investigations have shown that the Taylor-Quinney factor may vary significantly with strain and strain rate. ${ }^{[4]}$ In addition, most of the reported values are for room temperature deformation. The lack of precise knowledge of the Taylor-Quinney factor at hot-working temperatures can thus also introduce noticeable uncertainty into estimates of the temperature increase during hot forging.

\section{CONCLUSIONS}

Equiaxed- $\alpha$ performs of Ti-6Al-4V were forged to a 60 -pct. height reduction in a screw press to determine the effect of deformation heating on microstructure evolution. The temperature transients during forging were quantified experimentally and using FEM simulations. Based on these results, the following conclusions were drawn.

1. For the various billet sizes and preheat temperatures, substantial amounts of deformation heating are experienced during forging, resulting in transient exposure above the equilibrium $\beta$ transus temperature. Based on experimental temperature measurements using embedded thermocouples, the total time (forging + cooling) above the equilibrium $\beta$ transus is of the order of $\sim 5 \mathrm{~s}$. Simulation results suggest that some locations within the workpiece can even experience temperatures above the transus for $\sim 10$ seconds.

2. Despite the exposure above the $\beta$ transus, only small volume fractions of the equiaxed- $\alpha$ phase present during heating prior to forging are dissolved during forging and subsequent cooling.

3. Simulation predictions from a simple 1-D diffusion model reveal that the observed levels of $\alpha$-phase dissolution likely occur during forging. Even though this portion of the overall thermomechanical cycle is very short when using a screw press, dissolution is enhanced by the concurrent deformation/pipe diffusion and temperature increases associated with deformation heating.

4. Although longer in duration than the forging step, cooling through the $\beta$ phase field following forging per se appears not to bring about further $\alpha$-phase dissolution due to the possible development of a zero-diffusional-flux region in the vicinity of each equiaxed- $\alpha$ particle.

\section{ACKNOWLEDGMENTS}

This work was conducted as part of the CORE research program at the Advanced Forming Research Centre; financial support for this project from the Tier 1 members is gratefully acknowledged. The authors wish to thank the Advanced Forming Research Centre for granting permission to publish this manuscript. The assistance of Kornelia Kodziolka, Helge Jorgensen, and Stephen Waugh with metallographic sample preparation and screw press forging trials is acknowledged with gratitude. 


\section{CONFLICT OF INTEREST}

On behalf of all authors, the corresponding author states that there is no conflict of interest.

\section{OPEN ACCESS}

This article is licensed under a Creative Commons Attribution 4.0 International License, which permits use, sharing, adaptation, distribution and reproduction in any medium or format, as long as you give appropriate credit to the original author(s) and the source, provide a link to the Creative Commons licence, and indicate if changes were made. The images or other third party material in this article are included in the article's Creative Commons licence, unless indicated otherwise in a credit line to the material. If material is not included in the article's Creative Commons licence and your intended use is not permitted by statutory regulation or exceeds the permitted use, you will need to obtain permission directly from the copyright holder. To view a copy of this licence, visit http://creat ivecommons.org/licenses/by/4.0/.

\section{REFERENCES}

1. A.M. Sabroff, F.W. Boulger, and H.J. Henning: Forging Materials and Practices, Rheinhold Book Company, New York, 1968.

2. T. Altan, F.W. Boulger, J.R. Becker, N. Akgerman, and H.J. Henning: Forging Equipment, Materials, and Practices, Report MCIC-HB-03, Metals and Ceramics Information Center, Battelle's Columbus Laboratories, Columbus, OH, 1973.
3. G.I. Taylor and H. Quinney: Proc. R. Soc. Lond. A, 1934, vol. 143, pp. 307-26.

4. D. Rittel, L. Zhang, and S. Osovski: J. Mech. Phys. Solids, 2017, vol. 107, pp. 96-114.

5. C.K. Lieou and C.A. Bronkhorst: Paper submitted to Acta Mater., 2020.

6. N. Srinivasa and Y.V.R.K. Prasad: J. Mater. Process. Tech., 1995, vol. 51, pp. 171-92.

7. T. Seshacharyulu, S.C. Medeiros, W.G. Frazier, and Y.V.R.K. Prasad: Mater. Sci. Eng. A, 2000, vol. 284, pp. 184-194.

8. T. Seshacharyulu, S.C. Medeiros, W.G. Frazier, and Y.V.R.K. Prasad: Mater. Sci. Eng. A, 2002, vol. 325, pp. 112-25.

9 S.L. Semiatin, N.C. Levkulich, C.A. Heck, A.E. Mann, N. Bozzolo, A.L. Pilchak, and J.S. Tiley: Metall. Mater. Trans. A, 2020, vol. 51A, pp. 2291-2305.

10. S.L. Semiatin, N.C. Levkulich, and J.S. Tiley: Metall. Mater. Trans. A, 2021, vol. 52A, pp. 2238-60.

11. N.C. Levkulich, S.L. Semiatin, E.J. Payton, S. Srivatsa, and A.L. Pilchak: Metall. Mater. Trans. A, 2021, vol. 52A, pp. 1353-67.

12. J.M. Sosa, D.E. Huber, B. Welk, and H.L. Fraser: Integr. Mater. Manuf. Innov., 2014, vol. 3, pp. 123-40.

13. F. Bachmann, R. Hielscher, and H. Schaeben: Ultramicroscopy, 2011, vol. 111, pp. 1720-33.

14. S.L. Semiatin, F. Montheillet, G. Shen, and J.J. Jonas: Metall. Mater. Trans. A, 2002, vol. 33A, pp. 2719-27.

15. M. Kulakov, L. Da Silva, and A. Andreu: MATEC Web Conf., In Proceedings of the 14th World Conference on Titanium, 2020, vol. 321, paper\# 12003, 5 pages.

16. J.W. Elmer, T.A. Palmer, and J. Wong: J. Appl. Phys., 2003, vol. 93, pp. 1941-47.

17. A.I. Ismail, M. Dehmas, E. Aeby-Gautier, and B. Appolaire: In Proceedings of the 13th World Conference on Titanium, 2016.

18. M. Boivineau, C. Cagran, D. Doytier, V. Eyraud, M.H. Nadal, B. Wilthan, and G. Pottlacher: Int. J. Thermophys., 2006, vol. 27, pp. 507-29.

Publisher's Note Springer Nature remains neutral with regard to jurisdictional claims in published maps and institutional affiliations. 